\title{
Safety and effectiveness of transvenous lead extraction in elderly patients
}

\author{
Andrzej Kutarski ${ }^{1}$, Anna Polewczyk ${ }^{2}$, Krzysztof Boczar ${ }^{3}$, \\ Andrzej Ząbek ${ }^{3}$, Maciej Polewczyk ${ }^{4}$ \\ ${ }^{1}$ Department of Cardiology, Medical University of Lublin, Lublin, Poland \\ ${ }^{2} 2^{\text {nd }}$ Department of Clinical Cardiology, Swietokrzyskie Cardiology Center, Kielce, Poland \\ ${ }^{3}$ Department of Electrocardiology, John Paul II Hospital, Krakow, Poland \\ ${ }^{4}$ First Faculty of Medicine, Medical University of Warsaw, Poland
}

\begin{abstract}
Background: There is a considerable controversy regarding safety of transvenous lead extraction (TLE) in elderly patients due to their potentially worse general condition, more concomitant diseases, more difficult sedation or analgesia. Moreover, the present experience is not relevant. The aim of the study was the comparison of safety and feasibility of TLE in elderly and middle-aged patients.
\end{abstract}

Methods: We have extracted an ingrown pacemaker (PM)/implantable cardioverter-defibrillator (ICD) leads from 1,060 adult patients (21-70 years) and 192 octogenarians (mean age $83.4 \pm 3.1$ years) using standard mechanical systems within the last 7 years. We compared effectiveness and complications of the TLE procedures in the two mentioned groups of patients. Results: There were more women in octogenarians referred for TLE (45.3\% vs. 36.9\%). In addition, more pocket infections (37.0\% vs. 24.5\%), less non-infective indications for PM (46.9\% vs. $57.7 \%$ ) and ICD systems (7.3\% vs. 28.8\%) TLE were observed in this group. Leads body dwelling time was similar $(76.4 \pm 56.8$ vs. $83.5 \pm 63.0)$ in both groups. Procedure efficacy (full radiological success $97.4 \%$ vs. $94.6 \%$, partial radiological success $2.6 \%$ vs. $4.34 \%$ ), safety measures (major complications $1.6 \%$ vs. $1.51 \%$, minor complications $1.0 \%$ vs. $1.9 \%$ ) were similar in both compared groups.

Conclusions: Old age does not influence TLE effectiveness. Therefore, TLE can be safely and successfully performed in octogenarians. (Cardiol J 2014; 21, 1: 47-52)

Key words: transvenous lead extraction, permanent pacing complications, elderly, octogenarians

\section{Introduction}

The number of elderly patients with pacemaker (PM) and implantable cardioverter-defibrillator (ICD) remains still growing due to the global population aging, which results in increased subpopulation of elderly patients with late $\mathrm{PM} / \mathrm{ICD}$ complications, such as infections or other lead related complications [1]. Transvenous lead extraction (TLE) became a life-saving procedure in patients with device infection or other serious complications [2], and an accepted method of secondary prevention from lead related complications [3]. There is a considerable controversy

Address for correspondence: Anna Polewczyk, MD, PhD, $2^{\text {nd }}$ Department of Clinical Cardiology, Swietokrzyskie Cardiology Center, ul. Grunwaldzka 45, 25-736 Kielce, Poland, tel: +48 4136715 08, fax: +48 4136714 56, e-mail: annapolewczyk@wp.pl

Received: 11.03.2013 Accepted: 31.05.2013 
regarding TLE safety in elderly patients due to their potentially worse general condition, more concomitant diseases and additional difficulties in sedation or analgesia. Until now, there have been 4 available reports concerning safety and effectiveness of lead extraction in elderly patients [4-7]. Octogenarians are considered poor candidates for invasive procedures including TLE because of many comorbidities.

We aimed at evaluating the safety and effectiveness of TLE procedures in octogenarian patients in comparison to middle-aged population.

\section{Methods}

We performed retrospective analysis of data achieved from 1,289 consecutive patients referred to our reference center for TLE with infective or non-infective indications between March 2006 and January 2013. Indications for lead extraction and definition of procedural outcomes (i.e. success and complications) followed the Heart Rhythm Society (HRS) Expert's Consensus on transvenous lead extraction [8].

The patients population was divided into three age groups: 36 patients in the age below 20 years (young patients), 1,060 patients between 20-79 years (middle-aged, adults) and 192 patients 80 years old and more (octogenarian group). The first group was excluded from this study due to extreme differences in extraction of lead implanted in childhood and later, and we have compared only adults with octogenarians patients (1,252 patients). Baseline clinical and procedural data and outcomes were compared between these two age groups.

\section{TLE procedure}

After obtaining written informed consent, the TLE procedures were performed by one operator - previously trained and experienced electrophysiologist from referential center on late pacing complications management. Lead extraction procedures were performed under conscious sedation or analgesia. All mandatory safety procedures (e.g. blood cross-matched, invasive arterial pressure monitoring through arterial line, prepared chest operating field and other) were employed in case of more than 12 years old leads or diagnosed perforation; in this situation TLE procedures were performed in cardiac surgery operating room. TLE of younger leads was performed in electrophysiological laboratory with standard cardiac surgeon's team standby. Intraoperative echocardiography was performed at the discretion of the operator, and routine postoperative echocardiographic exam was performed every time on the next day.

The leads were extracted through a subclavian approach adopting 3 techniques. The first one was simple gentle manual screwing-out/traction, consisting of the removal of a lead using manual tools such as stylets (usually non-locking) only in case of leads implanted less than 2 years ago, and no need for recapture of subclavian venous entry. The second technique was extraction using cutting-rotation forces with mechanical sheath, consisting of lead removal through a polypropylene dilator sheath (Byrd, Cook Vascular Inc, Leechburg, PA, USA, all sizes and diameters), and both locking and non-locking stylets. The last technique represented other than lead venous entry approach and dedicated or non-dedicated tools for extraction of spontaneously broken leads with proximal ending dropped into the cardiovascular system and broken lead fragments from femoral, right jugular or preserved previous broken lead venous entry approach [9-11].

\section{Outcomes}

After TLE procedures, all patients were observed toward native heart rhythm stability and possibility of delayed symptoms of periprocedural major and minor complications. Definitions of major and minor complications were adopted from HRS Expert Consensus 2009 [8].

\section{Statistical analysis}

The values presented are expressed as mean \pm standard deviation (SD) for continuous variables showing normal distribution, and as frequencies and percentages for categorical data. Comparisons between the two age groups were performed using

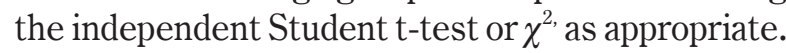

\section{Total population characteristics}

The whole study population consisted of 1,252 patients (774 males; $61.8 \%$ ) aged 21-94 (average $65.9 \pm 14.4$ ) years. Main indications for TLE procedures are summarized in Table 1.

Device infection was the main indication for lead extraction, and was present among 553 (44\%) cases. Most of TLE procedures were performed due to different non-infective indications (56\%). Data concerning non-infective indications were summarized in Table 1 . There were $392(31 \%)$ single chamber, 705 (56\%) dual chamber system, 145 (11\%) three chamber systems, and $7(0,6 \%)$ four chamber systems. We have noted 1 vacant lead in $145(11 \%), 2$ abandoned leads in $67(5 \%), 3$ or 4 in 
Table 1. Main indications for transvenous lead extraction (TLE) procedures.

\begin{tabular}{|c|c|c|c|}
\hline Main indication for TLE & Class of indication & Procedures & Percent \\
\hline Lead dependent endocarditis or sepsis & 1 & 223 & $17.81 \%$ \\
\hline $\begin{array}{l}\text { Pocket infection (abscess, skin erosion, chronic draining } \\
\text { sinus, skin adherence etc.) }\end{array}$ & 1 & 330 & $26.36 \%$ \\
\hline $\begin{array}{l}\text { Recovery of venous approach in case of bilateral subclavian } \\
\text { veins or VCS occlusion for transvenous lead implantation or } \\
\text { contraindication of collateral side usage (arterio-venous fistula, } \\
\text { vascular access port, mastectomy) or in case of no } \\
\text { contraindication for contralateral side use }\end{array}$ & 1 or $2 b$ & 87 & $6.95 \%$ \\
\hline VCS syndrome with limited symptoms & 1 & 4 & $0.32 \%$ \\
\hline $\begin{array}{l}\text { Lead which may pose an immediate threat for the patient } \\
\text { if left on site }\end{array}$ & 1 & 20 & $1.60 \%$ \\
\hline $\begin{array}{l}\text { Life threatening arrhythmias secondary to retained lead } \\
\text { or piece of the lead }\end{array}$ & 1 & 2 & $0.16 \%$ \\
\hline Lead interference with an active CIED system tumor therapy & 1 & 16 & $1.28 \%$ \\
\hline Chronic pain at device site & $2 a$ & 7 & $0.56 \%$ \\
\hline Implantation requiring more than 4 leads in SV, or over 5 in VCS & $2 a$ & 4 & $0.32 \%$ \\
\hline $\begin{array}{l}\text { Lead which may pose a threat to the patient if left in place, } \\
\text { prophylactic lead replacement }\end{array}$ & $2 b$ & 33 & $2.63 \%$ \\
\hline $\begin{array}{l}\text { Superfluous functional lead; extraction during CIED procedure } \\
\text { when contraindications are absent (excess of leads functional, } \\
\text { change of pacing mode, upgrading) }\end{array}$ & $2 b$ & 52 & $4.15 \%$ \\
\hline $\begin{array}{l}\text { Superfluous lead non-functional; extraction during CIED } \\
\text { procedure when contraindications are absent (dislodgement, } \\
\text { exit/entry block, permanent AF, defective/damaged, } \\
\text { overmuch nonfunctional) }\end{array}$ & $2 b$ & 459 & $36.66 \%$ \\
\hline $\begin{array}{l}\text { Missed tip location (out of standard position), } \\
\text { symptomatic perforation }\end{array}$ & 3 & 15 & $1.20 \%$ \\
\hline All TLE procedures & & 1,252 & $100 \%$ \\
\hline
\end{tabular}

$\mathrm{AF}$ — atrial fibrillation; CIED — cardiac implantable electronic devices; SV — subclavian vein; VCS — vena cava superior

$7(0.8 \%)$ cases. The total number of extracted leads was 2,137 , matching on average $1.8 \pm 0.78$ leads per patient. We have removed 914 atrial leads, 1145 right ventricular leads, and 78 left ventricular coronary sinus leads.

\section{Results}

The main clinical characteristics of the study population sorted according to age (octogenarians vs. younger adult patients) and the main procedural data and outcomes are summarized in Table 2.

The difference between the mean age in both groups was over 21 ( 83 vs. 62 ) years, likewise, the difference between the median (83 vs. 66 years). There were only $478(38.2 \%)$ females in the whole population referred for TLE procedures, however, women were significantly dominant among octogenarians $87 / 192(45.3 \%)$ than younger patients $391 / 1060$ (36.9\%). The proportion of device-related sepsis/endocarditis were similar in both compared groups, yet, the percentage of pocket infection (abscess, skin erosion, chronic draining sinus, skin adherence etc.) was higher in octogenarians (37.0\% vs. $24.5 \%)$. Non-infective indications (recapture of venous approach, potentially dangerous lead, lead interference with other system or with management of malignancy, excess of functional or non-functional leads, symptomatic venous occlusion) were less frequent in octogenarians than in other adult patients ( $46.9 \%$ vs. $57.7 \%$ ). Complexity of the system was understood as the number of leads in heart before lead extraction (active and abandoned leads). The number of extracted leads in 1 patient, number of leads in the system before TLE (only active leads) and number of abandoned leads before TLE were similar in both compared groups of patients. Likewise, coronary sinus lead presence/extraction did not differ between the groups ( $16.1 \%$ vs. $15.3 \%)$. The type of the device also differed significantly in the two age groups, with lower rate of ICDs among octogenarians $(7.3 \%$ vs. $28.8 \%)$. Additionally, we evaluated preoperative chest X-ray examination to look for too 
Table 2. The main clinical characteristics of the study population sorted according to age (octogenarians vs. younger adult patients) and the main procedural data and outcomes.

\begin{tabular}{|c|c|c|c|}
\hline Patient/system/procedure information & $\geq 80$ years & $21-79$ years & $\mathbf{P}$ \\
\hline Number of patients & 192 & 1060 & - \\
\hline Patient's age & $83.4 \pm 3.10$ & $62.7 \pm 13.4$ & 0.000001 \\
\hline Sex - males ( $\%$ of male patients) & $105(54.7 \%)$ & $669(63.1 \%)$ & 0.0331 \\
\hline Infective endocarditis, sepsis & $31(16.1 \%)$ & $189(17.8 \%)$ & 0.6446 \\
\hline $\begin{array}{l}\text { Pocket infection (abscess, skin erosion, chronic draining } \\
\text { sinus, skin adherence etc.) }\end{array}$ & $71(37.0 \%)$ & $259(24.5 \%)$ & 0.0004 \\
\hline $\begin{array}{l}\text { Non-infective indications (recapture of venous approach, } \\
\text { dangerous lead, lead interference, overmuch of functional } \\
\text { or non-functional leads, symptomatic venous occlusion) }\end{array}$ & $90(46.9 \%)$ & $611(57.7 \%)$ & 0.0072 \\
\hline Number of leads in heart before lead extraction & $2.06 \pm 0.77$ & $2.01 \pm 0.81$ & 0.4280 \\
\hline Number of extracted leads in 1 patient & $1.78 \pm 0.86$ & $1.70 \pm 0.81$ & 0.2126 \\
\hline Number of leads in the system before TLE & $1.84 \pm 0.65$ & $1.81 \pm 0.66$ & 0.561433 \\
\hline Number of abandoned leads before TLE & $0.26 \pm 0.61$ & $0.24 \pm 0.59$ & 0.6673 \\
\hline CS (LA, LV) lead extraction & $31(16.1 \%)$ & $162(15.3 \%)$ & 0.8446 \\
\hline High voltage therapy (ICD) lead extraction & $14(7.3 \%)$ & $305(28.8 \%)$ & 0.000001 \\
\hline $\begin{array}{l}\text { Too long loops of lead in right heart cavities with } \\
\text { double lead crossing of tricuspid valve }\end{array}$ & $11(5.7 \%)$ & $74(7.0 \%)$ & 0.6322 \\
\hline Number of procedures before lead extraction & $1.99 \pm 1.23$ & $1.95 \pm 1.22$ & 0.6764 \\
\hline Mean leads body dwelling time [months] & $76.4 \pm 56.8$ & $83.5 \pm 63.0$ & 0.1451 \\
\hline Full radiological success & $187(97.4 \%)$ & $1002(94.6 \%)$ & 0.1354 \\
\hline Partial radiological success & $5(2.6 \%)$ & $46(4.34 \%)$ & 0.3571 \\
\hline Major complications & $3(1.56 \%)$ & $16(1.51 \%)$ & 0.7907 \\
\hline Minor complications & $2(1.00 \%)$ & $20(1.88 \%)$ & 0.6019 \\
\hline $\begin{array}{l}\text { Technical problems during TLE (extracted lead breakage, } \\
\text { extracted lead fragmentation and its removal in parts, } \\
\text { polypropylene sheath facture, lead to lead strong connection } \\
\text { with connecting tissue scar, dislodgement of functional } \\
\text { lead, problem with sheath passing via lead subclavian } \\
\text { entry, necessity to change of venous approach etc.) }\end{array}$ & $28(14.6 \%)$ & $172(16.23 \%)$ & 0.6421 \\
\hline Operating room stay-in time (whole procedure duration) [min] & $103.9 \pm 45.7$ & $111.4 \pm 47.7$ & 0.0776 \\
\hline
\end{tabular}

ICD — implantable cardioverter-defibrillator; CS — coronary sinus; LA — left atrium; LV — left ventricle; TLE — transvenous lead extraction

long loops of lead in right heart cavities, double lead crossing the tricuspid valve. The phenomenon not only disturbs tricuspid valve functionality, but also may render lead extraction difficult and favor tricuspid system damage during TLE. The percentage of this faultiness was similar in both groups $(5.7 \%$ vs. 7.0\%). System duration expressed as mean leads body dwelling time and number of procedures (unit replacements, upgrades, lead replacements, etc.) before lead extraction were similar (76.4 vs. 83.5 months and 1.99 vs. 1.95 procedures).

Table 2 contains analysis and comparison of procedural outcomes. Full radiological success (extraction of all leads) was very high and similar in both compared groups (97.4\% vs. 94.6\%). Percentages of partial radiological success, indicating tip of the lead or piece of the lead shorter than $4 \mathrm{~cm}$ left in the atrial or ventricular wall with full clinical success in all cases were similar (2.6\% vs. $4.3 \%)$.
A total of $17(1.35 \%)$ major complications occurred among 1,252 TLE procedures in the periprocedural period, consisting of $4(0.31 \%)$ deaths. The major complications were: 12 cardiac tamponade (9 cardiac surgeries, 3 pericardial drainages, 2 patients died in spite of a successful operation), 1 massive pulmonary embolism and 1 severe hypotonia and contractility depression (both patients died), 2 hemothoraces as results of vena cava tear ( 1 thoracotomy) and 1 cerebral stroke. Additionally, 1 patient died 2 weeks after effective TLE procedure as a result of severe recurrence of sepsis after the new system implantation.

Major complications occurred in identical percentage in octogenarians and in other adult patients ( $1.56 \%$ vs. $1.51 \%)$.

Minor complications occurred in 19 (1.52\%) patients, and consisted of 6 diminutive heart wall tears with asymptomatic epicardial fluid not re- 
quiring drainage, 4 aggravations of tricuspid valve dysfunction, 3 vena cava tears causing small right pleural effusion not requiring drainage, 3 mild pulmonary embolisms diagnosed in computer tomography not requiring intervention, 2 vascular tears causing local thrombosis with conservative treatment, and 1 intraoperative bleeding requiring pre-discharge blood transfusion. No statistically significant differences in the rates of minor complications were found between octogenarians and younger patients group (1.00\% vs. $1.88 \%$ ).

Difficulty of TLE procedure represents frequency of appearance of technical problems, which prolongs procedure and usually enforces the operator to use additional tools and additional vascular approach as well. Percentage of transient technical problems, which occurred during TLE procedure was similar in both groups of patients $(14.6 \%$ vs. $16.2 \%)$. The whole TLE procedure duration time expressed as average operating room stay-in time was nearly identical (103.9 vs. $111.4 \mathrm{~min})$.

\section{Discussion}

To the best of our knowledge, this is the $5^{\text {th }}$, and the largest study (significantly longer implant duration in the described patients also seems to be important) reporting the safety and effectiveness of TLE in octogenarians, similar to previous 4 reports [4-7], that advanced age does not affect the safety and efficacy of TLE procedures. As in previous reports, the problem of optimal management of old patients with different late pacing complications still remains controversial. On the one hand, longer population life-time prompts an increase of the number of $\mathrm{PM} / \mathrm{ICD} /$ cardiac resynchronization therapy (CRT) recipients, and consequently multiplies further procedures (unit replacements, system upgrades, lead replacements and other). The number of elderly patients presenting device-related infection or malfunction eligible for lead extraction is expected to increase [1-3]. On the other hand, old age and associated comorbidities of implantable cardiac device recipients restrains form referral for TLE, especially in cases of non-infective indications. Kennergren et al. [12] reported that in some patients TLE was not performed only because of advanced age. In a recent European survey we have also articulated concerns about the age as an independent factor inclining the operator to avoid TLE if possible [13].

Our study demonstrated significantly more women among octogenarians (45.3\%) than among younger patients (36.9\%). It might be the effect of longer mean life-span in women than in men. Nevertheless, higher percentage of female patients (known TLE complications risk factor) did not influence frequency of TLE complication. It is difficult to explain higher frequency of pocket infections (37.0\% vs. $24.5 \%)$ in octogenarians. The rate of these patients' reference for TLE due to other non-infective indications may be lower. In spite of similar system complexity in both groups of patients, we noted a lower rate of ICDs among octogenarians ( $7.3 \%$ vs. $28.8 \%$ ).

System duration in our patients expressed as mean leads body dwelling time (76.4 months in octogenarians and 83.5 months in younger adult patients) is significantly longer than in 4 cited reports [4-7].

We have presented that effectiveness of TLE procedures expressed as percentage of radiological success (97.4\% vs. $94.6 \%)$ and percentage of partial radiological success but with full clinical success were similar (2.6\% vs. $4.3 \%$ ). Major complications occurred in identical percentage in octogenarians and in other adult patients ( $1.56 \%$ vs. $1.51 \%)$, similarly did minor complications (1.00\% vs. $1.88 \%$ ). The TLE in octogenarians was not connected with additional technical problems ( $14.6 \%$ vs. $16.2 \%)$ and the whole procedure duration was similar in older and younger patients (103.9 vs. $111.4 \mathrm{~min}$ ).

The largest reports of Pelargonio et al. [4], Rodriguez et al. [6], and Williams et al. [7] indicate that the majority of patient population underwent lead extraction because of device-related infection, which represents a mandatory indication for lead extraction. In contrast, $47 \%$ of our octogenarian patients were referred for TLE due to non-infective indications.

Important part of the TLE procedure consists of sedation/analgesia and periprocedural intensive care. The role of experienced anesthesiologist cannot be underestimated.

\section{Authors impression}

We have an impression never to meet significant calcification of connecting tissue scar surrounding over 12 years old lead in octogenarians. It was a relatively frequent finding in adult patients, particularly before $3^{\text {rd }}$ and $4^{\text {th }}$ decade. The lack of this phenomenon may partly explain a relatively high effectiveness of TLE using mechanical tools only. This, however, was not analyzed in this study.

\section{Limitations of the study}

Our study included a retrospective analysis of data from consecutive patients referred to 
a single center specialized in the management of late permanent cardiac pacing complications. Due to positive opinion of our center and previous educational effort on management of late PM/ICD/CRT complications, the role of referring doctors seems to be limited and we may believe that only small percentage of elderly patients were not referred due to worse general conditions and multiple comorbidities. Similar schedule of indications for TLE in both age groups seems to confirm this concept.

It is important that procedures were performed only by one experienced operator, and the results should not be generalized to other, less-experienced centers and operators.

\section{Conclusions}

Transvenous lead extraction has similar efficacy and safety in octogenarians as in younger patients. Advanced age per se should not restrict the utility of lead extraction therapy in patients with late $\mathrm{PM} / \mathrm{ICD} / \mathrm{CRT}$ complications.

\section{Conflict of interest: none declared}

\section{References}

1. Kurtz SM, Ochoa JA, Lau E et al. Implantation trends and patient profiles for pacemakers and implantable cardioverter defibrillators in the United States: 1993-2006. Pacing Clin Electrophysiol, 2010; 33: 705-711.

2. Nery PB, Fernandes R, Nair GM et al. Device-related infection among patients with pacemakers and implantable defibrillators:
Incidence, risk factors, and consequences. J Cardiovasc Electrophysiol, 2010; 21: 786-790.

3. Gould PA, Krahn AD; Canadian Heart Rhythm Society Working Group on Device Advisories: Complications associated with implantable cardioverter-defibrillator replacement in response to device advisories. JAMA, 2006; 295: 1907-1911.

4. Pelargonio G, Narducci ML, Russo E et al. Safety and effectiveness of transvenous lead extraction in octogenarians. J Cardiovasc Electrophysiol, 2012; 23: 1103-1108.

5. Kempa M, Budrejko S, Piepiorka M et al. Safety and effectiveness of transvenous extraction of pacemaker and implantable cardioverter-defibrillator leads in patients under and over 80 years of age. Kardiol Pol, 2013; 71: 130-135.

6. Rodriguez Y, Garisto JD, Carrillo RG. Laser lead extraction in the octogenarian patient. Circ Arrhythm Electrophysiol, 2011; 4: 719-723.

7. Williams SE, Arujuna A, Whitaker J et al. Percutaneous extraction of cardiac implantable electronic devices (CIEDs) in octogenarians. Pacing Clin Electrophysiol, 2012; 35: 841-849.

8. Wilkoff BL, Love CJ, Byrd CL et al. Heart Rhythm Society, American Heart Association: Transvenous lead extraction: Heart Rhythm Society expert consensus on facilities, training, indications, and patient management: This document was endorsed by the American Heart Association (AHA). Heart Rhythm, 2009; 6 : 1085-1104.

9. Kutarski A, Pietura R, Mlynarczyk K et al. Pacemaker lead extraction and recapture of venous access: technical problems arising from extensive venous obstruction. Cardiol J, 2012; 19: 513-517.

10. Kutarski A, Pietura R, Czajkowski M. Breakage of extracted leads: another management option. Kardiol Pol, 2012; 70: 307-312.

11. Kutarski A, Czajkowski M, Tomaszewski A et al. Extraction of a 17-year-old pacing lead chronically dislocated into the liver vein. J Vasc Access, 2012; 13: 130-131.

12. Kennergren C, Bjurman C, Wiklund R et al. A single-centre experience of over one thousand lead extractions. Europace, 2009; 11: 612-617.

13. van Erven L, Morgan JM. Scientific Initiatives Committee (SIC): Attitude towards redundant leads and the practice of lead extractions: A European survey. Europace, 2010; 12: 275-276. 